\title{
What Role Should Teachers Play in Online Teaching during the COVID-19 Pandemic? Evidence from China
}

\author{
Jijun Yao, ${ }^{1}$ Jialong Rao, ${ }^{2}$ Tao Jiang, ${ }^{3}$ Changqian Xiong ${ }^{3}$
}

1. Nanjing Normal University, Nanjing 210024, Jiangsu, China

2. Sichuan Duofen Education Research Institute, Chengdu 610011, Sichuan,

China

3. Guiyang No.8 Middle School, Guiyang 550003, Guizhou, China

\begin{abstract}
After the outbreak of the COVID-19 pandemic, China implemented the largest online education practice in human history. In the process, different teaching models coexist. Through a quasi-natural experiment, a total of 1,024 samples from Guiyang No.8 Middle School and another comparable school with the same conditions and students were enrolled for analysis, we discussed the impact of two online teaching methods, recorded video versus live broadcasting, on student performance, and the role teachers should play in online teaching. The study found that, compared with the self-study-based recorded video teaching, live broadcasting teaching with more teacher-student interaction is a more conducive to improving students' academic performance. In the process of online teaching, teachers should not only assume the role of transmitting knowledge, but also play the role of "leader" and "accompanier" through effective guidance and communication.
\end{abstract}

Sci Insigt Edu Front 2020; 5(2):517-524.

Doi: 10.15354/sief.20.ar035

Keywords: COVID-19; Online Teaching; Teacher Role; Recorded Video;

Live Broadcasting; Academic Performance

About the Authors: Jijun Yao, Professor, School of Educational Science, Nanjing Normal University, Nanjing 210024, Jiangsu, China. Email: yaojijun_njnu@163.com.

Tao Jiang, Teacher, Guiyang No. 8 Middle School, Guiyang 550003, Guizhou, China. Email: 591414783@qq.com. 


\section{Question}

7 EACHERS play an important role in the teaching process. In John Hattie's famous book "Visible learning: A synthesis of over 800 meta-analysis relating to achievement" (2009), the author analyzed the influence of teachers on academic performance. He found that teachers' teaching strategies and methods have a significant impact on student performance. Among them, the interactive teaching method has the largest impact on performance among all other teaching strategies, with an effect size of 0.74. In the teaching process, teachers' timely feedback and formative evaluation provided the greatest impact on the academic output, with effect size of 0.73 and 0.90 , respectively. The academic community attaches great importance to students' autonomous learning, whereas Haiti's analysis showed that self-controlled learning by students themselves may not be an effective way to improve academic output, and its effect size was only 0.04 .

Hattie's study did not discuss at length the impact of teacher behavior on academic performance under online teaching conditions. In recent years, cumulating evidence showed that online teaching had convincing role in improving students' performance. Cheng et al. (2019) conducted a systematic review and meta-analysis of the published data and found that almost all the use of technology plays a role in improving students' academic achievement. Compared with students who do not use technology or use traditional teaching methods, the use of technology could help students improve their academic performance by 15.5 percentage points. Other studies have found that the use of information technology could also improve student performance, as well as help reduce inequality in education (Fang, et al., 2019; Tian, et al., 2020). Currently, most of these studies used technology as a booster for the transformation of the teaching from the "teacher-centered" to the "student-centered" process. Of this, teachers could use information technology to help students improve their academic output via giving students more autonomy in learning to achieve the transition from "leaders" to "helpers" of learning (Tian, 2018).

So, can technology further play an independent role, or even replace teachers to achieve students' completely autonomous learning? With the advent of online teaching formats such as MOOC, such assumptions are no longer unlikely like Arabian nights. Even some more radical views believe that in the future, with the help of artificial intelligence, virtual teachers can replace most of the roles of offline teachers do (Yu, 2018).

About the Authors: Changqian Xiong, Teacher, Guiyang No. 8 Middle School, Guiyang 550003, Guizhou, China. Email:316663718@qq.com.

Correspondence to: Jialong Rao, Researcher, Sichuan Duofen Education Research Institute, Chengdu 610011, Sichuan, China.Email: raojl@moofen.cn.

Funding: Jiangsu University Discipline Construction Project Funding Project (PAPD).

Conflict of Interests: None. 
Zhou et al. (2018) used large-scale academic monitoring data and found that the teacher-student relationship is the most essential factor that affects student performance. This means that technology is playing an increasing role, but the effective communication between teachers and students face-to-face is still indispensable and is a critical link for students' learning process.

But to date, most of the research on this issue has been carried out only in the presence of teachers. It is not clear whether technology plays a role of "replacement" or "reinforcement" for teachers. Furthermore, we have no way to know what role teachers should use to get into student's learning process with the help of technology if teachers are completely "absent"? However, it is difficult to get a complete answer to this question because the "absence" of the teacher cannot be realized in a normal course of teaching.

The sudden outbreak of COVID-19 at the end of 2019 forced schools to close. The Chinese government has adopted the "School's Out, But Class's On" approach, i.e. "suspending classes without stopping learning", to provide online learning tutoring for students at home. This largest online teaching activity in human history has made tens of millions of teachers and students have to complete the conversion from offline teaching to online teaching overnight. Teachers and students no longer meet each other as usual. Regardless of whether or not they are willing, teachers have to quickly adapt to this change in teaching methods and switch the accompanying role. Such a large-scale online teaching practice provides us with a good opportunity to explore the abovementioned issues. We can use this to examine how teachers and technology should be combined under online teaching conditions. In other words, what role should teachers play in order to better achieve the teaching goals and improve students' academic performance? We will explore this through a quasi-experiment.

\section{Study Design}

\section{Experiment Objective}

The main purpose of our research is to investigate the ways in which teachers organize teaching under online teaching conditions to better improve student performance. During the COVID-19 pandemic, all schools in China adopted online teaching methods, but the methods adopted by different schools were different. Generally, there are two basic online teaching modes. One mode is "Recorded Video", from which the teacher recorded the class contents in advance and the students watched them online themselves. During this process, there was no online communication between teachers and students, and the delivery of contents was single direction. Students totally relied on self-study to complete learning tasks. In this case, teachers were more likely to assume the role of content providers. The other mode is "Live Broadcasting", through which teachers use teaching software to teach online. During teaching, the real-time interaction and communication with students was realized. Students could complete learning tasks with the guidance and assistance of their teachers. In this way, the teacher still plays the role of a 
student's learning guide or even a leader; and the immediate teacher-student interaction enabled the teacher to play the role of "accompany" in the learning process. We hereto compare the effect of these two teaching modes on student performance to analyze what role teachers' play in online teaching, which will help improve the teaching efficiency and student performance.

\section{Experimental and Control Groups}

In this study, the live broadcasting mode in which teachers were more involved in learning was used as an intervention variable to set the experimental group and compare the teaching effect with the Recorded Video mode. For this reason, we chose Guiyang No.8 Middle School and another comparable school with the same teaching conditions and students as the experimental subjects. These two middle schools are all high schools in Guiyang City, and the school's running conditions, teachers, and student resources are relatively close. In the experimental course, after matching, we took samples of senior students from the two schools to make the results of the students in the two schools comparable. By comparing the differences in teaching effectiveness between the two schools during the pandemic, we could determine which form of online teaching is more conducive to improving student performance. Among them, Guiyang No.8 Middle School mainly used Live Broadcasting to organize teaching during the pandemic, and it was set as an experimental group; another school with the same school conditions and student sources mainly used Recorded Video to organize teaching, which was set as the control group. During the pandemic, the content, progress, and prior and posterior testing tools of the two schools were consistent, thereby ensuring that the experimental results were comparable. A total of 1,024 student samples were enrolled from both schools. Since China senior high school students are taught in literal and science classes separately, so we divided the total samples into two sub-groups: literal and science. Among them, there were 209 in the literal experimental group and 221 in the control group; 294 in the science experimental group and 300 in the control group.

\section{Experimental Process}

During the pandemic, Guiyang No. 8 Middle School and another peer school complied with the requirements of the Chinese Ministry of Education for "School's Out, But Class's On" and the unified deployment of the Guiyang Education Bureau. Since February 3, 2020, online teaching has been implemented totally. By mid-March, 2020, Guiyang's epidemic prevention and control had achieved remarkable progress, and social life gradually returned to normal. The school resumed on March 16th, 2020, and so the 6-week online teaching and e-learning was over. The students returned to school and switched to the normal offline teaching.

During the online teaching, the experimental group and the control school implemented teaching according to a unified schedule. However, the experimental group, Guiyang No. 8 Middle School, was mainly based on live broadcasting, supplemented by a small amount of recorded video. Live broadcasting accounts for more than $70 \%$ of the 
total teaching time. The peer school in the control group mainly used the recorded videos that are available on various teaching platforms or recorded by the teachers of the school, supplemented by a small amount of live Q \& A, so the recorded video accounted for more than $80 \%$ of the total teaching time. After the beginning and end of the experiment, both groups performed prior test (pretest) and posterior test (post-test), and the tests were standardized uniformly.

\section{Results and Discussion}

\section{Pretest Results}

The test results of the experimental group and the control group are shown in Table $\mathbf{1}$. Table 1 presents the results of the mean, standard deviation, and independent sample $t$ test. The results showed that, except for the Chinese language scores of the science samples, the average and total test scores of the subjects in the experimental group were lower than those in the control group; however, the results of the independent sample $t$ test showed that the difference was not significant ( $p>0.05)$. This shows that the experimental conditions were good, and it was possible to more accurately analyze the impact of teachers in the experimental group that showed more involvement in online teaching through analyzing the post-test results.

\section{Post-Test Results}

The post-test results in Table 2 show that after 6 weeks of online teaching, the experimental group surpassed the peer control group in both the total and the average scores in each subject. This shows that the online teaching in the experimental group had achieved better results, and the students in the experimental group had made greater academic progress during the pandemic. The difference in performance between the two groups changed from insignificant at the beginning to significant at the end of the study $(\mathrm{p}<0.001)$.

\section{Discussion of the Results}

In fact, due to the urgency of the epidemic, when online teaching was implemented, although each school made a lot of preliminary preparations, because this was an unprecedented exploration, teachers and students had never been in such a long time to solve teaching problems online. Therefore, it was not clear what kind of teaching mode would be used to improve teaching efficiency. It should be said that for most schools in China, the online teaching activities carried out during the pandemic were of a certain experimental nature.

Because of this, in this online teaching practice in China, various forms of teaching have appeared. As mentioned earlier, live broadcasting and recorded video were the two most common modes. In recent years, due to the rapid development of online education resources and technology, various views on the role of teachers had 


\begin{tabular}{|c|c|c|c|c|c|c|c|c|c|c|}
\hline \multirow{2}{*}{$\begin{array}{l}\text { Sub- } \\
\text { Sample }\end{array}$} & \multirow{2}{*}{ Subject } & \multicolumn{2}{|c|}{$\begin{array}{l}\text { Sample } \\
\text { Size }\end{array}$} & \multicolumn{2}{|l|}{ Mean } & \multicolumn{2}{|l|}{ SD } & \multirow{2}{*}{$t$} & \multirow{2}{*}{$p$} & \multirow{2}{*}{$\begin{array}{l}\text { Cohen's } \\
d\end{array}$} \\
\hline & & Exp. & Ctrl. & Exp. & Ctrl. & Exp. & Ctrl. & & & \\
\hline \multirow[t]{4}{*}{$\begin{array}{l}\text { Literal } \\
\text { L }\end{array}$} & Chinese & \multirow{4}{*}{209} & \multirow{4}{*}{221} & 74.785 & 78.009 & 41.618 & 38.054 & 0.839 & 0.402 & -0.081 \\
\hline & Math. & & & 51.297 & 55.955 & 33.620 & 33.371 & 1.441 & 0.150 & -0.139 \\
\hline & English & & & 74.726 & 80.507 & 43.768 & 42.563 & $\overline{1.388}$ & 0.166 & -0.134 \\
\hline & Total & & & 200.808 & 214.471 & 114.845 & 109.479 & 1.263 & 0.207 & -0.122 \\
\hline \multirow[t]{4}{*}{ Science } & Chinese & \multirow{4}{*}{294} & \multirow{4}{*}{300} & 89.364 & 87.227 & 21.634 & 27.088 & 1.061 & 0.289 & 0.087 \\
\hline & Math. & & & 64.561 & 64.867 & 24.238 & 30.904 & 0.134 & 0.894 & -0.011 \\
\hline & English & & & 90.815 & 92.712 & 24.836 & 32.037 & 0.805 & 0.421 & -0.066 \\
\hline & Total & & & 244.740 & 244.805 & 59.871 & 81.810 & 0.011 & 0.991 & -0.001 \\
\hline
\end{tabular}

been put forward in the information age. The substantive difference behind the two online teaching modes examined in this study was the difference of teachers' roles. Compared with recorded video, the relationship between teachers and students in the live broadcasting was much closer to the traditional way, and the only difference was the delivered knowledge lies in different means of technology.

Our experimental results showed that in the current online teaching process, more teachers' involvement is an effective way to improve teaching efficiency. From the calculation results in Tables $\mathbf{1}$ and 2, compared with the control group in which students had greater autonomy, the experimental group had more explaining and giving feedback online in time, which may be the main reason that leads to higher performance. This result also showed that although the development of information technology provides students with greater space and resources for autonomous learning, teachers' teaching and feedback still play a critical role. From this perspective, in online teaching, it is not enough for teachers to play the role of knowledge or resource providers, like offline courses, teachers also play a role as a mentor and a companion.

\section{Conclusions and Implications}

In response to the problems in online education during the COVID-19 pandemic, we based on a sample of 1,024 students from Guiyang No. 8 Middle School and another peer comparable school with the same school conditions and students. Through this 6week quasi-experiment, we found that: 


\begin{tabular}{|c|c|c|c|c|c|c|c|c|c|c|}
\hline \multirow{2}{*}{$\begin{array}{l}\text { Sub- } \\
\text { Sample }\end{array}$} & \multirow{2}{*}{ Subject } & \multicolumn{2}{|c|}{$\begin{array}{l}\text { Sample } \\
\text { Size }\end{array}$} & \multicolumn{2}{|l|}{ Mean } & \multicolumn{2}{|l|}{ SD } & \multirow[t]{2}{*}{$t$} & \multirow{2}{*}{$P$} & \multirow{2}{*}{$\begin{array}{l}\text { Cohen's } \\
d\end{array}$} \\
\hline & & Exp. & Ctrl. & Exp. & Ctrl. & Exp. & Ctrl. & & & \\
\hline \multirow[t]{4}{*}{ Literal } & Chinese & \multirow{4}{*}{209} & \multirow{4}{*}{221} & 89.617 & 78.719 & 26.421 & 34.260 & 3.679 & 0.000 & 0.355 \\
\hline & Mathematics & & & 76.785 & 66.294 & 23.793 & 31.620 & 3.871 & 0.000 & 0.374 \\
\hline & English & & & 105.242 & 94.333 & 23.349 & 35.458 & 3.746 & 0.000 & 0.361 \\
\hline & Total & & & 271.644 & 239.346 & 57.185 & 91.720 & 4.353 & 0.000 & 0.420 \\
\hline \multirow[t]{4}{*}{ Science } & Chinese & \multirow{4}{*}{294} & \multirow{4}{*}{300} & 92.585 & 85.450 & 14.600 & 28.797 & 3.797 & 0.000 & 0.312 \\
\hline & Mathematics & & & 77.124 & 69.413 & 19.270 & 30.458 & 3.679 & 0.000 & 0.302 \\
\hline & English & & & 102.182 & 94.690 & 24.722 & 32.042 & 3.186 & 0.002 & 0.262 \\
\hline & Total & & & 271.891 & 249.553 & 44.641 & 82.655 & 4.086 & 0.000 & 0.355 \\
\hline
\end{tabular}

Note: Exp.: Experimental Group; Ctrl.: Control Group; SD: Standard Deviation.

First, in the current online teaching process, simply providing teaching resources is not enough. Taking more live broadcasts to form more teacher-student communication and instant feedback is an effective way to improve student performance. Second, for teachers, in the process of online teaching, more attention and feedback should be given to students to form an effective online communication mechanism. Only in this way can we achieve the teaching goals more efficiently.

Our findings apply not only to online teaching during the pandemic, but also to offline teaching. Under the condition that the experimental group and the control group are basically the same in all aspects, the most crucial factor for the difference in student academic performance is the difference between the teacher and student communication of the two groups during the online process. This further enlightens us on how to build a good teacher-student relationship, form a smooth teacher-student communication, and enable teachers to truly assume the role as a mentor and a companion, which is the real key to the effective teaching.

\section{References}

Chen, W., Fan, Z., Chen, Y., Zhuang, R., Huang, R. (2019) Retracing the controversy between technology and learning:
The discovery of integrated meta-analysis. E-Edu Res, 40(6):35-42 
Fang, C., Wang, G., Huang, B. (2019) Can information technology promote the development of students' cognitive ability? An estimate based on the net effect of educational value-added measurements. Open Edu Res, 25(4):100-110.

Hattie, J. (2015) Visible Learning: A synthesis of over 800 meta-analysis relating to achievement (Chinese version). Beijing: Educational Science Publishing House. 189, 232.

Tian, S. (2018) The role of teachers in the mobile Internet environment must be triple-turned. Chin Edu J, 39(7):103
Tian, Y, Yao, J., Ding, J. (2020) How the school's information technology hardware investment affects students' achievements: Based on the empirical research of Nanjing middle school. Edu Res Month, 37(1):87-94.

Yu, S. (2018) The future role of artificial teachers. Open Edu Res, 34(1):16-28

Zhou, S., Gu, H., Yao, J. (2018) From "strict learning" to "smart learning": an analysis of the key factors affecting students' academic performance: an empirical study based on the academic quality monitoring data of 262245 students in Jiangsu province. Prim Mid Sch Manag, 32(11):39-42.

Received: 11 March 2020

Revised: 16 March 2020

Accepted: 24 March 2020 